\title{
EU policies in personalized medicine-related
} technologies

\begin{abstract}
Against the background of a number of first drug-diagnostic co-products developed and introduced into the European market, European decision-makers feel impelled to react and position themselves in the field of personalized medicine. Their reactions cover a broad range, from the analysis of knowledge requirements for market approval to the need for translational activities and the possible contribution of pharmacogenetics to public health. This article summarizes the current positions of European institutions, based on literature revlew and expert consultation for three items associated with personalized medicine: biobanks; genetic diagnostics and drug-diagnostic co-products, and provides an outlook on requirements for an effective future European policy on personalized medicine:
\end{abstract}

\section{KEYWORDS: biobanks, clinical utility: clinical validity; drug-diagnostic co-development, effectiveness, European policy, framework conditions, genetic diagnostics, translational research}

Against the background of a number of first drug-diagnostic co-products developed and introduced into the European market, European decision makers feel impelled to react and position themselves in the field of personalized medicine, which aims to use information about a patient's genotype or gene-expression profile to tailor medical care to the individual's needs. Despite a number of regulations already in place, robust scientific evidence on developmenr, use and demand of genomic applications is still lacking. Consequently, reactions of decision-makers cover a broad range, from the analysis of knowledge requirements for market approval to the assessment of translational activities and the determination of expected effects of broad (pharmaco) genetic testing for public health.

This paper presents some results from a report commissioned by the Institute for Prospective Technological Studies (IPTS) of the Joint Research Centre (JRC) of the European Commission [101]. The goal of this report was to identify current gaps in European research and regulation to ensure that emerging genomic applications, including many associated with personalized medicine, will be brought into clinical practice with a high level of evidence available regarding; safery, analytical validity and clinical validity (when relevant), effectiveness, clinical urility and cost-effectiveness. Ethical, legal and social (ELS) issues were also identified, all within the goal to maximize benefits for European patients and contribute to consensus-forming among relevant stakeholders. Furthermore, the report examined similarities in such evidence-generating processes as applied to a relatively broad range of genomic applications, in an effort to mark some common ground for the activities comprised in the ill-defined concept of translational research. A baseline model of this process was provided by Khoury and colleagues [1].

Many authors have highlighted how translational efforts need to strike a balance between generating evidence on the actual benefits, costs and ELS issues of new applications, on the one hand, and promoting and supporting an increased rate of innovation, on the other hand $[2,102]$. The authors' assessment is that the first goal has been subject of much less resenrch and support (see also [3]).

This article aims firstly to present the technical and institutional barriers to rranslational research that were identified in the report for a selected set of technologies. A second goal is to provide an overview of the position of European insticutions, focusing on how they may affect evidence generation for effective translation of these technologies into practice. Ir can thereby contribute to the development of an effective European policy on personalized medicine, and the concerted action of different stakeholders in the field. Some of the applications that are particularly associated with personalized medicine are the focus of the current analysis: biobanks, genetic diagnostics and drug-diagnostic coproducts. These applications were chosen as

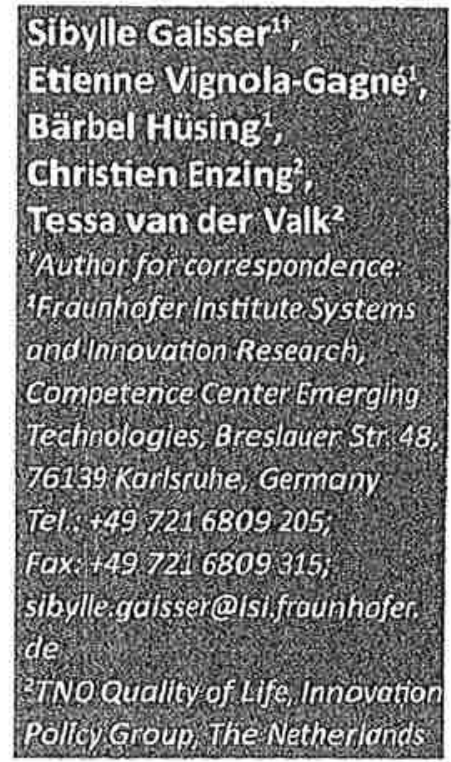

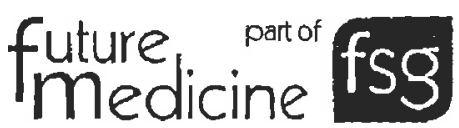


they have already resulted in personalized medicine products, and seem to be currently under political consideration.

Information on the issues relevant for these different applications was gathered by means of a literature search, using the databases Web of Science and PubMed to identify sciencific publications, and an internet search for policy reports. This information was complemented by consultations with 19 experts (researchers, patient organizations, healthcare providers, industry representatives and experss from governmentassociated institutions). These experts were from Austria, Belgium, Denmark, Germany, Italy, the Nerherlands, Spain, Switzerland and the UK. They were asked to identify relevant issues, as well as reflect on the issues apparent from the literature search.

\section{Technological basis}

Biobanks consist of repositories of tissue, cell or genome samples with associated molecular, physiological and structural information [103]. They form large systemic ensembles of technologies that are used to allow for high-volume genorype-phenotype associations. These repositories are scheduled to play a central role in providing raw data that is used in fundamental and translational genomic research, and which will form the basis for the development of personalized therapies.

Generic testing is based on the determination of one or several DNA sequences. It identifies changes in chromosomes, genes or proteins. Genetic testing summarizes the different diagnostic applications of genomic technologies (i.e., DNA- and RNA-based testing, such as diagnostic testing, predictive testing, susceptibility testing, gene-expression profiling carrier testing, prenatal testing, newborn screening, presymptomatic screening and infectious diseases resting). Other applications without a direct link to medicine are in the field of paternity and forensic resting. Whereas some applicarions, such as genetic screening (both for newborns, and in the case of presymptomatic screening for adults), do not have a direct link to personalized medicine, others, such as diagnostic and susceptibility resting, are clearly associared with, or are even a prerequisite for, personalized medicine. Gene-expression profiling also firs in this latter caregory, with promising applications for personalized medicine in oncology, and more specifically breast cancer, recently gaining relatively broad use $[4,5]$ and progressively being reimbursed in Europe, according to one developer [104]. Additionally, protein assays and immunoassays often benefit from the development of genetic diagnostics, as once a gene is identified as being part of a disease process, the products of the gene and downstream metabolites can be identified. The resuling tests could also be beneficial for personalized medicine.

Finally, drug-diagnostic co-products refer to drugs and biopharmaceuticals that are labeled for use in combination with a specifically designed diagnostic test, both on a genetic and/ or biochemical or immunohistochemical basis (as described above). Such testing may be used to decide whether or not a drug should be prescribed (i.e., whether a drug fits the individual patient's biology) and to decide on the appropriate dosage. Drug-diagnostic co-products are the key elements towards personalized medicine, as has been shown for a number of cancer and AIDS treatments, such as tamoxifen, trastuzumab, cetuximab and ochers (for a more detailed list, see [6]). While the category of genetic testing can include pharmacogenetic tests, drugdiagnostic co-products can be singled out as a specific technological area in cases of simultaneous development or commercialization of both components.

\section{Barriers to evidence generation \& relevant European policy activities Biobanking}

Biobanks are currently perceived in a number of European policy and scientific circles as playing a major role in establishing the knowledge of gene-disease associations that will enable some key advances in preventive and personalized medicine [104]. More specifically, it is often felt that these associations require very large repositories, and networks of repositories, of samples collected in a standardized manner to enable the kind of robust prospective studies that will be required in the case of polygenic, common chronic diseases [2]. A number of technical and institutional barriers have been identified as potentially hampering the establishment of these networks and their full integration into translational research efforts:

- Lack of standardization of complex and vastly differing biobanking systems in Europe;

- Difficulties in standardization and establishment of quality assurance protocols for data collection in biobanks;

- Obstacles in the emergence of the professional field of databank management; 
- Uncertainties linked to ethical issues;

- Obstacles to ensuring demographic representativeness of data sets.

Following the rationale presented above, a major scientific and policy concern has recently been the harmonization and standardization of various activities (e.g., sampling, recoding lifestyle and environmental data) in biobanking [105,106], which seems to be the most appropriate way to obtain these large data sets. A number of activities in this respect can be identified at the European leve].

A concept paper presenting porential guidelines for the use of biobanks for pharmacogenetics was drawn up by the European Medicines Agency (EMEA) in 2005 with issues concerning procedures for collecting, storing, handling and analyzing samples; 'implications of removing from samples and data identifying information in preand post-authorization assessment of medicinal products'; and qualicy assurance and quality control [107]. Another important source of efforts to cstablish guidelines for biobanks has been the Organization for Economic Co-operation and Development [103], and the guidelines of this international organization have gained some prominence [7].

The European Cornmission, through its Seventh Framework Programme (FP7), is set to encourage the increased integration and nerworking of existing national biobanks in Europe, as well as the use of these biobanks by actors in the field, such as population geneticists [108]. However, in 2006 the following deficits were observed: the lack of a comprehensive inventory of biobanks and disease registries in Europe, as well as the lack of a catalogue on exiscing regulations pertaining to ethics, confidentiality and security requirements [108], despire previous suryeys of biobanks [8]. Recent harmonization initiatives have sought to provide answers to such concerns. One example is the Biobanking and Biomolecular Resources Research Infrastruccure (BBMRI), supported by the FP7, which started its preparation phase in early 2008 . The initiative involves, among others, institutions such as UK Biobank, deCODE generics, the Icelandic biobank and the Estonian Biobank, for a total of over 50 participants and external partners, including also other biobanks, national ministries, hospitals, biomolecular biology research institutions, companies, ELS issues research centers, and so forth, distributed across Europe (see [109] for a list). The initiative's goal is to link together European national collections of data and samples that are underutilized owing to fragmentation. It is also interesting to noce that the mix of actual repositories and relevant stakeholders in these networks is representative of a number of other initiatives, such as the Public Population Project in Genomics $\left(\mathrm{P}^{3} \mathrm{G}\right)$, which includes biobanks from Canada as well as Europe, or EuroBioBank, with biobanks focusing on rare diseases. They may hopefully pave the way for increased awareness of some of the issues associated with translational research within what may become foundational activities for personalized medicine.

Efforts to set up biobanks have been subject to many problems and debates [2]. Although there are expectations that biobanks will eventually lower costs for public health systems by improving the prevention and treatment of diseases [2], the enormous cost of setting up these initiatives has caused great criticisms [9,110]. The scientific grounds on which ir is expected that biobanks can make a major contribution to establishing associations between genes, environment and lifestyle and the etiology of some common chronic diseases have been dispured, in terms of both sciencific soundness and feasibility [9,10] and, perhaps more importantly for the argument developed here, in terms of actual clinical utility of the knowledge generated in a clinical context [2].

Several orher potential issues with European biobanks have been identified, notably by Taylor, such as a conflict of current practices with the EU Directive on data protection (95/46/EC) [1] . $\mathrm{He}$ argues that these issues will become more acute as biobanks expand and are used more intensively. Concerns have also been voiced that differences between $\mathrm{EU}$ member states in the national regulations on biobanks may hamper academic research and industrial development $[11,111]$. This may also hamper collection of evidence when assessing products for clinical validity and clinical urility $[12]$, and as such it might be worthwhile to conduct research on how to achieve a balance between acadernic and industrial research interests and needs on the one hand, i.e., the role of biobanks in future fundamental and translational research on genomics products, and privacy regarding personal data and benefit sharing on the other hand [13-15].

\section{Diagnostics}

A number of well-defined technical and institutional barriers to evidence generation on genetic diagnostics could be identified for the six dimensions of interest described in the introduction (safety, analytical and clinical validity, 
effecriveness, clinical utility, cost-effectiveness). Translational research in this area of applications has benefited from a number of reflections and initiatives, as well as previous experiences with monogenic genotype-phenotype associations, although evidence for polygenic associations is still very much in the early stages. The following points provide a summary of these barriers, which are ourlined in more detail in the complete report:

- Uncertainties regarding the safety of drugs rescued with pharmacogenetic tesring;

- Lack of participation of physicians/laboratory staff in proficiency testing and quality assurance schemes, and lack of appropriate methods for tests where no gold standard exists;

- Knowledge gaps on genotype-phenotype associations, with associated problems for validation of biomarkers;

- Knowledge gaps in human genome epidemiology and associated results replication, especially for complex diseases;

- Lack of a commonly used validation procedure such as clinical trials to generate practical, premarket evidence for genetic tests;

- Lack of translational research on genetic tests, including complex diagnostic tools such as in vitro diagnostic multivarjate index assays (IVDMIA) [112];

- Unfamiliarity of actors with the dimension of effectiveness as an important dimension in translational research for diagnostic products;

- Knowledge gaps on penetrance and prevalence of certain generic diseases;

- Broad dearth of assessments on the clinical utility of genetic diagnostics;

- Lack of coordination and guidelines on the assessment of clinical utility;

- Lack of postmarker monitoring schemes to contribute data for the assessment of clinical utility of genetic diagnostics;

- Inadequacy of current evidence generation for and number of assessments of cost-effectiveness of genetic diagnostics.

Looking at how current European policy activities may impact evidence generation for genetic diagnostics, Directive $98 / 79 / \mathrm{EC}$ on in vitro diagnostic devices (IVD) establishes the framework for diagnostics regulation in Europe [113]. It provides the regularory framework for the examination of analytical validity of diagnostic products and, for those tests deemed moderate or high-risk, their eventual premarket review for $\mathrm{CE}$ certification [111]. Despite this directive, EU Members States vary vastly when it comes to the regulation of in-vitro diagnostics, as illustrated in the case of inherited genetic disorders [16]. In the USA, there seems to be a more stringent coverage of generic resting from research to product approval under the authority of the US Department of Health and Human Services (an analysis of these USA-Europe differences, however, exceeds the scope of this arricle). A number of problems and potential developments for reforming regulation of diagnostics are thus currently being studied in Europe, as will be discussed below.

Collecrion of data of analytical and clinical validity is made difficult in Europe by the lack of a compulsory systematic premarket review of genetic diagnostic products, harmonized across EU Member States. The IVD Directive does not require most of these tests to undergo review, because the large majority are classified as low risk [102]. The exception is a small number of blood-screening tests considered as high risk and other tests considered as moderate risk. In the case where a test would be classified as moderate or high risk, Conformité Européenne (CE) marking is made following a premarket review, which concentrates on analytical validity and that is accomplished by companies that act as 'Notified Bodies'. Regulations in the EU do not require manufacturers of genetic tests to demonstrate clinical validity if no clinical claims are made [102]. A test can claim to identify a gene with no requirement to explain the clinical relevance of this claim [114]. Hogarth and coworkers reported that the IVD Direcrive is not limited to analytical validity and does in practice ask for proof of clinical effectiveness when reviewing diagnostic applications [115]. The authors come to the conclusion that, in the end, there is significant ambiguity in what is required by the IVD Directive. At any rate, for the few diagnostics where premarket review nust be performed by notified bodies, there would also be little room to ask for data on clinical urility and cost-effectiveness as is currently set out for diagnostic products.

Generating evidence on validity and utility of djagnostics also faces specific problems for homebrew tests, which account for a significant portion of diagnostic services in Europe (111]. The problem of quality control of homebrews developed by individual laboratories - initially 
reported for the USA - seems also to be important in Europe, and the way in which quality assurance measures guaranteeing analytical and clinical validity can be put into place [i1]]. While in principle these diagnostic services would normally need to comply with the safery and efficacy requirements set out by IVD Directive, public health institutions can be exempted from applying the directive when offering homebrews as part of their services [102].

In the face of such gaps in the generation of evidence available on diagnostic tests, certain authors (mostly from the USA) have indeed suggested calling for greater levels of evidence than is currently provided by sponsors when assessing diagnostic products, notably in evaluations conducted to make reimbursement decisions [17 19,116]. A report by Melzer and colleagues mentions interview results with stakeholders in Europe that show a lack of linkage between premarket review of pharmacogeneric applications, health technology assessment (HTA) activities and reimbursement decisions [117]. Improving evidence generation on pharmacogenetic tests, and genetic tests more broadly, and tying this process more closely to reimbursement decisions, would indeed parallel what is being observed in the case of drugs and therapeutic products in Europe [20]. The PHGEN network [118] has for its part proposed to establish:

- Platforms and processes for generaring data and evidence to support the evaluation of tests;

- Mechanisms to set and agree standards for the clinical validity and utility of tests;

- Methodologies and facilities for the epidemiological evaluation of their clinical validity and urility;

- Policies for test evaluation that will set out the respective roles of government, industry and academia $[119]$.

Perhaps as a move to address some of these gaps, the Directorate General for Enterprise of the European Commission (DG Enterprise) has recently consulted with relevant actors of the sector for a potential revision of the IVD Directive, as well as other medical devices directives [120], Eventual changes of particular interest could include a modification of the risk classification of IVDs [102], providing the EMEA with jurisdiction over the regulation of IVDs and medical devices, and merging the IVD directive with the two other medical devices directives. Both measures could result in more widespread and more harmonized (or indeed cencralized) premarket review of diagnostic products. They may also prove to be appropriate vehicles for increased evaluations of clinical validity, effectiveness, clinical utility and cost-effectiveness of diagnostics. These proposals have, however, been subject to debates, as some fear that they may also entail additional regulatory burdens for product sponsors in an industry that relies on fast market entry [121], or that the EMEA's expercise lay in medicinal products and not medical devices, which could be considered a very different type of product $[122,124]$.

In view of the additional burden that such an approach may put on test developers, orher potential avenues for stimularing the generation of evidence have also been proposed, such as the use of the patent system to promore clinical studies that provide data on the clinical validity of the genotype-phenorype associations supporting genomic diagnostic applications [2]]; or using a responsive, risk-based regulatory approach that would, for example, call for refined labeling schemes for genetic tests $[22,23]$. Clarifying the roles of actors who have been responsible for generating evidence on diagnostics in Europe (Notified Bodies and Comperent Authorities, reimbursers and professional bodies) may also contribure to translational research [102]. EuroGentest [123] has also been active in sponsoring workshops to find solutions to improve European provisions on genetic testing [102,125]. This organization has also been very acrive in ongoing efforts to improve standardizarion and external assessment schemes for genetic testing products across Europe. Finally, the US Secretary's Advisory Committee on Genetics, Healrh, and Sociery (SACGHS) has recently produced reports on pharmacogenomics [126], which may prove to have a certain impact on reflections on evidence generation for these applications in Europe, as the success of the ACCE framework seems to indicate [16].

\section{Drug-diagnostic co-products}

Drug-diagnostic co-products pose a unique challenge in terms of evidence generation, with each component belonging to very different innovation and regulation frameworks, as will be explained below. The technical and institutional barriers and knowledge gaps for translational research on drug-diagnostic co-products include, in addition to the barriers mentioned for diagnostics:

- Knowledge gaps in analyrical validity and clinical validity compromising safety in the use of co-products; 
- Insufficient numbers of epidemiological studies and replication studies performed in pharmacogenetics;

- Increased complexity compared with the drug and diagnostic parts.

Despite the fact of clear regulations for (bio) pharmaceuticals [127] and biosimilars [128,129] in the EU, experts observed the lack of a framework for drug-diagnostic co-products in Europe [24]. As mentioned above and in an earlier report [111], developments related to drug-diagnostic technologies may prove problematic for the EMEA since these two product types fall under two separated legislative frameworks. While drugs can be approved either by a national examination followed by a mutual recognition process or by the centralized European process, diagnostic producrs are examined for their analytical validity and their compliance with CE regulation (IVD Direcrive, see [11t]) by national authorities. This has led to drugs being approved by the EMEA but not the relevant pharmacogenetic test, for which the EMEA has no competence to do so [114]. In the case where a diagnosric might be envisaged as compulsory or strongly recommended before the prescription of a drug, the EMEA would only be able to act on the drug's label, and could not make the test mandatory. With the whole field of genetic testing attracting attention at the European level, however, EMEA experts have for a certain time recognized that there may be a possible need for a formal communication channel berween the EMEA and national authorities in order to improve regulation of drug-diagnostic co-products in a pharmacogenetic context, for example [111].

The Pharmacogenetics Working Party of the Committee for Medicinal Products for Human Use (CHMP) has established briefing meetings that allow applicants for regulatory approval of medicines to hold informal discussions with EMEA experts regarding the technical, scientific and regulatory issues arising from the inclusion of pharmacogenetic tests in the development of these products. These meerings have no impact on the regulatory process, but are intended to reduce obstacles in the use of pharmacogenetic tests, while providing the Working Party's experts with more data about the rationale and circumstances in which pharmacogenetic data are generated [130]. Such meetings can also be organized with both US and European regulatory bodies in joint FDA-EMEA voluntary genomic data submission (VGDS) briefing meetings (131]. The impact of these meetings is intended to be both in specific product guidance as well as in future guidance on pharmacogenetics. From the standpoint of translational research, these meetings offer the porential to generate further data on drug-diagnostic co-products, most probably in the aspects of analytical validity, clinical validity and perhaps clinical utiliry of the diagnosric component. From the US side, the aforementioned SACGHS report on pharmacogenomics does contain recommendations on evidence generation specific to drug-diagnostic co-products that may have impacts in Europe [126].

In the case of drug-diagnostic co-produets, however, current policy-makers may be more concerned about lagging behind in the rate of new innovarions. As previous studies have reported, pharmacogenetics, for example, is only slowly gaining ground in clinical practice [111]. Aside from a certain reservation in the context of use, development of drug-diagnostic coproducts is also complicated by the fact that the drug and diagnostic components each belong to different innovation and regulation systems. Philips, Van Bebber and Issa provide an analysis of some of the problems faced in the diagnostic pipeline (although regulatory issues are situated in a US context) [25].

On this front, the Innovarive Medicines Initiative, set up by the European Commission and the European Federation of Pharmaceutical Industries and Associations (EFPIA), is an initiative that may have a positive impact on the development of personalized medicine in Europe [132]. With a budget of $€ 2$ billion, its goal is to reinvigorate the European pharmaceutical sector through the development of research consortiums. One scientific priority of the initiative is to develop pharmacogenetics in order to increase the safety and efficacy of new drugs, and to allow for reduced scope and duration of clinical trials, as well as to allow for preventive trials [133].

\section{Future perspective}

With scientific and technical progress in genomics and its application in diagnostics and drugs, the need for a clear and consistent European policy towards personalized medicine becomes obvious. As the case of genetic testing for inherited disorders illustrates [16], current policies provide a rather fragmented framework that will not be adequate to cover all relevant issues mentioned above.

In order to overcome the obstacles resulting from the aforementioned barriers and promote the efficient uptake of personalized medicinerelated technologies, EU-level policies are being 
considered to establish a research framework for improved translational activities. Some potential goals of these research activities identified were:

$s$ The production of more evidence in clinical validity of tests performed in clinical settings and the genotype-phenorype associations they are based on (when relevant), effectiveness, clinical utility and cost-effecriveness of genomic applications, accompanied by the development of improved methodologies to assess the aforementioned dimensions;

- The development of clear guidance on data handling with respect to informed consent, securing confidentiality and security of the individual but also with regard to fragmentation of knowledge and professional management of biobanks.

It is expected that the biomarker-associated knowledge/technology basis will increase the understanding of biological processes relevant for complex diseases. This will lead to new hypotheses and thus accelerate the pharmaceutical research and development process. However, the majority of these biomarker-based findings will not lead automatically to personalized medicines. In fact, only a small number of companies are currently active in the field of systematic research in personalized medicines. This lack of interest may be explained by the fact that the assessment of the benefits and risks of personalized medicines among stakeholders from industry, policy, academia and healthcare providers is contradictory. A systematic foresight of future developments in a scenario or roadmapping process initiated by European decision makers could be beneficial to overcome uncertainties.

The barriers idencified in personalized medicine-related technologies showed that there is a lack of evidence of clinical validity and utility, effectiveness and cost-effectiveness. This knowledge can only be generated in a multiand inter-disciplinary approach to international collaborations. In the European context, this is especially important considering how such evidence will most probably be generated at national levels rather than at the EU level. Continued coordination of evidence generarion and diffusion acrivities may thus be desirable. More to the point, it may be expected that evidence generarion for translational research will take the form of a loose style of governance centered around infrastructure for the diffusion and pooling of evidence produced by a variery of actors. These efforts may be achieved by the development of specific research infrastructures and the implementation of scandards, proficiency testing and quality assurance schemes, for example. Additionally, it will be essential to link separate platform-or biomarker-specific comperences with an integrated knowledge base that works from a problem-oriented rather than a technology-oriented angle.

A high volume of monogenic and polygenic tests acting as companions to drugs are expected to reach a development stage that allows market launch in the next years. However, according to expert opinion, positive public health effects can only be realized if sufficiencly validated tests are broadly marketed in the health sector. Thus, it will be crucial within the next $10-15$ years to set the appropriate framework for an efficient uptake of validated tests from basic research into the health sector. This involves the provision of adequate resources for clinical research and health technology assessment, the development of methodologies for evidence generation and the feedback between clinical research, basic research and strategic research funding.

Personalized medicine is a field with a high degree of individualization in the meaning of customized design for specific preferences or features of the individual person or group of persons. Against this background, it is remarkable that little research was carried out in the past on patient preferences and parients' expected utilization of personalized medicine. It seems important to integrate these issues in EU research policies and address the user perspective in the design of the technology and the framework conditions, by involving different stakeholder groups in the process of policy and research development [26,134].

Active and self-determined utilization of a new technology such as personalized medicine implies the availability of commonly understandable information [27-29]. Thus, part of future activities in personalized medicine should be the development and distribution of neurral, comprehensible and targeted information on applications in personalized medicine in an early phase of market penetration. An avenue for further research might be to check the possibility of an internet-based registry that contains all information submitted during the approval process, in the wake of a similar initiative for registering information on clinical trials $[30,31]$. However, this would require the adjustment of present legislation, as dossiers that are submitted for product approval are kept confidential under currently applicable law. 
Executivesinimary

\section{Introduction}

- Biobanks, genetic diagnostics and drug--diagnostic co-products are an important knowledge and technology basis of personalized medicine.

\section{Barriers to evidence generation \& relevant European policy activities}

- The European Commission FP7 framework programme has encouraged the increased integration and networking of European biobanks, but comprehensive inventories and disease registries in Europe are still lacking. The Biobanking and Biomolecular Resources Research Infrastructure may contribute towards closing this gap.

- The majority of genetic diagnostics are classified as low risk. Thus, they do not undergo compulsory premarket review.

- Drug-diagnostic co-products are not handled within one regulatory body.

\section{Future perspective}

- In order to promote the efficient uptake of personalized medicine-related technologies, the generation of more evidence in clinical validity is required both of tests performed in clinical settings and the genotype-phenotype associations they are based on (when relevant), also effectiveness, clinical utility and cost-effectiveness of genomic applications. Thus, it will be crucial within the next 10-15 years to set the appropriate framework in place for an efficient uptake of validated tests from basic research into the health sector.

- Evidence generation should be supported by the development of improved methodologies for the assessment of clinical validity, clinical utility and (cost)-effectiveness.

- Current barriers in the use of biobanks should be overcome by the development of clear guidance on data handling with respect to informed consent, securing confidentiality and security of the individual, but also with regard to fragmentation of knowledge and professional management of biobanks.

- Only a small number of companies are currently active in the field of personalized medicine. A systematic foresight of future developments in a scenario or roadmapping process initiated by European decision-makers could be beneficial to overcome contradictory assessment of the benefits and risks of personalized medicines.

- It will be essential to link separate platform- or biomarker-specific competences to an integrated knowledge base that works in a problem-oriented rather than technology-oriented manner.

- Patients' preferences should be included in EU research policies; the user perspective should be addressed in the design of the technology and the framework conditions by involving different stakeholder groups in the process of policy and research development.

- Active and self-determined utilization of personalized medicine implies the availability of commonly understandable information. It could be an option for decision makers to check the possibility of an internet-based registry that contains all information submitted during the approval process.

\begin{abstract}
Acknowledgements
The authors thank all people who took the time to participate to the interviews. This research was set up on the initidtive of the Institute for Prospective Tecbnological Studies (IPTS) of the Eurapedn Commission and conducted within ETEPS AISBL - the European techno-economic policy support network. The views expressed bere are those of the autbors and do not necessarily reflect the views of the European Commission.
\end{abstract}

Financial \& competing interests disclosure The authors bave no relevant affiliations or financial involvement with any organization or entity with a financial interest in or financial conflict with the subject matter or materials discussed in the manuscript. This includes employment, consultancies, honoraria, stock ownership or options, expert testimony, grants or patents received or pending, or royalties.

No writing assistance was witilized in the production of this manuscript.

6 Jorgensen JT: From blockbuster medicine to personalized medicine. Personalized Med. 5(1), 55-63 (2008). and problems of biobanks. Personalized Med. $4(4), 463-469$ (2007).

3 Khoury MJ, Bradley LA: Why should genomic medicine become more evidence-based? Genomic Med, 1(3-4), 91-93 (2007).

4 Marchionni L, Wilson RF, Wolff AC et al.: Systematic Reyiew: Gene expression profiling assays in early-stage breasc cancer. Ann. Jntern. Med. 148, 358-369 (2008).

5 Shak S: Introducing a genomic innovation to clinical pracrice. In: Diffusion and use of genornic innovations in bealth and medicine workshop summary. Hernandez L (Ed.). The Narional Academies Press, Washington, DC, USA, 51-58 (2008).
- Good overview on recens products and developments in personalized medicine.

7 Rebulla P, Lecchi L, Giovanelli S, Butti B, Salvaterra E: Bjobanking in the year 2007. Transfius. Med. Hemother. 34, 286-292 (2007).

8 Hirczling I, Dubreuil C, Préauberr $N$ es al: An empirical survey on biobanking of human generic material and data in six EU countries. Eur. J. Hum. Genet. 11, 475-488 (2003).

9 Barbour V: UK Biobank: a projecr in search of a protocol? Lnncet 361, 1734-1738 (2003).

10 Buchanan AV, Weiss KM, Fullerton SM: Dissecting complex disease; the quest for the research into the clinical practice. 
philosopher's stone? Int. J. Epidemiol. 35 , 562-571 (2006).

11 Taylor MJ: Regulating personal data in a shared world: limitations of the EU's approach to data protection. Personalized Med. 4(4), 47]-477 (2007).

u* Interesting analysis of European data-protection policies with respect to genomic data and biobanks.

12 Joly Y, Knoppers BM: Pharmacogenonic dara sample collection and storage: ethical issues and policy approaches. Pharmacogenomics $7(2), 219-226$ (2006).

13 Dowdeswell E, Daar AS, Acharya T, Singer PA: Realising the promise of genomics: Exploring governance. Int. J, Biorechnology. $8(1-2), 132-141$ (2006).

14 Hoedernaekers R, Gordijn B, Pijnenburg $M$ : Does an appeal to the common good justify individual sacrifices for genomic research? Theor. Med. Bioeth. 27(5), 415-431 (2006).

15 Porteri C. Borry P: A proposal for a model of informed consent for the collecrion, storage and use of biological materials for research purposes. Patient Educ, Conns. 71(1), 136-142 (2008).

16 Jahaver P, Kääriäinen $H$, Kristoffersson U ct al.: EuroGentest: DNA-based testing for herjtable disorders in Europe. Community Genet, 11, 75-120 (2008).

17 Garrison L, Austin MJF: Linking pharmacogenetics-based diagnostics and drugs for personalized medicine. Health Affairs 25(5), 1281-1290 (2006).

- Illustration of factors that explain the slow uptake of genomics technologies for personalized medicine.

18 Ginsburg GS: 'Grand challenges' in the translation of genomics to human healch. Eur. f. Hum. Genet. 16, 873-974 (2008).

19 Gudgeon JM, McClain MR, Palomaki GE, Williams MS: Rapid ACCE: Experience with a rapid and structured approach for evaluating gene-based tescing. Genet. Med. 9, 473-478 (2007).

20 McCabe C, Bergmann L, Bosanquet N et al.: Marker and pacient access ro new oncology producrs in Europe; a current, multidisciplinary perspecrive. Ann Oncol. forchcoming (2008) (Epub ahead of print).

21 Liddell K, Hogarth S, Melzer D, Zimmern R: Patents as incentives for translational and evaluative research: the case of generic tests and their improved clinical performance. Intellectual Property Quarterly (2008) (In press).

22 Hogarth S, Liddell K, Ling T, Sanderson S, Zimmern R, Melzer D: Closing the gaps enhancing the regulation of genetic tescs using responsive regularion. Food Drug Law J. $62,831-848(2007)$
23 Melzer D, Hogarth S, Liddell K, Ling T, Sanderson S, Zimmern RL: The new common disease generic tests: new insights, old concerns. BMJ 336, 590-593 (2008).

- Comprehensive analysis of requirements for the appropriate use of genetic testing.

24 Arnold HP, McHale D: Pharmacogenetics: Development issues and solucions for safe and effective medicines. Pharmacogenomics 7(2), 149-155 (2006).

25 Phillips KA, Van Bebber S, Issa AM; Diagnostics and biomarker development: priming the pipeline. Nat. Rev. Drug Discovery 5, 463-469 (2006).

26 Boon WPC: Demanding dynamics: Demand articulation of intermediary organisations in emerging pharmaceutical innovaions. $\mathrm{PhD}$ thesis, Faculty of Geosciences, Utrecht University, The Netherlands (2008).

27 Gigerenzer G, Edwards A: Simple rools for understanding risks; from innumeracy to insighc. BMJ 327(7417), 741-744 (2003).

28 Hoffrage $U$, Lindsey $S$, Hertwig $R$, Gigerenzer G: Medicine: Communicating sratistical information. Science 290(5500), 2261-2262 (2000).

29 Lipkus IM: Numeric, verbal, and visual formats of conveying health risks: suggested best pracrices and future recommendations. Med. Decis. Mnking 27, 697-714 (2007).

30 Krleza-Jeric K: Clinical Trial Registration: The Differing Views of Industry, the WHO, and the Ortawa Group, PLoS Med. 2(11), 1093-1098 (2005).

31 Lemmens T, Bouchard RA: Mandatory clinical trial registration: rebuilding crusr in medical research. In: Global Forum Update on Research for Health Volume 4. Global Forum for Health Research (Ed.), Pro-Book Publishing Limited, London, UK, 40-46 (2007).

\section{Websites}

101 Enzing C, Van der Valk T, Gaisser $S$, Vignola-Gagné E, Paci D, Ibarreta D: Genomics knowledge for furure bealsh services. Reporr commissioned by the European Commission Joint Research Centre Institute for Prospective Technological Studies, Seville, Spain (2008)

www.isi.Ahg,de/c/projekte/ e-SGA-genomic-knowledge.hum; forthcoming ar: http://ipts.jrc.ec.europa,eu

102 Hogarth S, Melzer D: The IVD Direcrive and generic resting: problems and proposals, A briefing presented to the: 20 th meeting of Competent Authoritics. Lisbon, Portugal, July 5-62007 (2007) www.eshg.org/documents/BriefingIVD DireciiveFINAL_july_20071.pdf [Accessed November 12, 2008]
103 Organisarion for Economic Co-operation and Development (OECD): OECD Best Practice Gridelines for Biological Resource Centres (2007)

htrp://www.oecd.org/darnoecd/7/13/ 38777417.pdf

[Accessed November 12, 2008]

104 Agendia: Agendia's MammaPrint breast cancer prognosis test cleased by U.S. Food and Drug Administracion (2007) hetp://row.agendia.com/en/archiv_07/ agendias_mammaprinc_breast_cancer_ prognosis_test_cleared_by_u.s._food_and drug_adminiscration_fda_hthl [Accessed November 5 2008]

105 Eutopean Science Foundation. Population Surveys and Biobanking. Science Policy Briefing 32 (2008) www.esf.org/research-areas/medical-sciences/ acrivities/science-policy/population-surveyand-biobanking.hminl [Accessed November ]2, 2008]

106 Stoltenberg C: Coordination Action: Harmonising population-based biobanks and colfort studies to strengthen the foundation of Entropean biomedical science in the post-genome cra. Population Biobanks (2003) www.p33gconsorium.org/events/ 2003Manchester/LifeSciHealth-Population_ Biobanks.pdf [Accessed Noyember 5, 2008]

107 European Medicines Agency (EMEA): Concept paper on the development of a guideline on biobanks isstes relevant so pharnacogeneties. EMEA/CHMP/6806/05 (2005) www.emea.europa,eu/pdfs/human/ pharmacogenetics $/ 680605$ en.pdf [Accessed February 19, 2008]

108 European Commission and Wellcome Trust: From Biobanks to Biomarkers. Transhating the Potentinl of Human Populntion Genetics Research to Improve the Quality of Health of the EU Citizen. Proceedings of a conference held at che Wellcome Trust Conference Centre, Hinxton, Cambridge, UK, 20-22 Seprember 2005 www.welicome.ac,uk/About-us/Publications/ Books/Biomedical-science/WTX032108.hrm [Accessed November 12 2008]

109 Zarloukal K: Biobanking and Biomolecular Resoutces Research In frastructure (BBMRJ). Proposal for: Combination of collaborative project and coordination and support action. Construction of new infrastructures preparatory phase (2007) www.biobanks,eu/cv/BBMRI_V55_web\%20 site.htm

[Accessed August 15, 2008]

110 Ghosh P; Will biobank pay off? $B B C$ Nevus, September 242003 htep://news.bbc,co.uk/2/low/health/ 3134622.stm [Accessed November 5, 2008] 
111 Hopkins $M M$, Lewis $G$, Gaisser $S$ ct al.: Regulatory and Quality Assurance Frameworks for PGx: A Comparative Study of the US, EU, and Four Member States. Parr 3 of an ESTO Study of Pharmacogenetics and Pharmacogenomies: Srate of the Art and Socjal and Economic Impacts (2006) htrp://frp.jrc.cs/pub/EURdoc/eur22214wp3. $\mathrm{pdf}$

[Accessed November 12, 2008]

- Syropsis on genetic testing regulation in some of the leading countries involved in pharmacogenetics and pharmacogenomics based on case studies for USA, UK, the Netherlands, Ireland and Germany supplemented by an industry view on regulatory issues.

112 US FDA: Drafi Guidance for Industry, Clinical Laboratories, and FDA Staff: In Vitro Diagnostic Multivarinte Index Assays (2007) www.fda.gov/cdrh/oivd/guidance/16]0.pdf [Accessed November 12, 2008]

- This document specifies in vitro diagnostic multivariate index assays (IVDMIA) as a device that combines the values of multiple variables using an interpretation function to yield a single, patient-specific result (e.g., a 'classification', 'score' and 'index'), that is intended for use in the diagnosis of disease or other conditions, or in the cure, mitigation, treatment or prevention of disease, and provides a result whose derivation is nontransparent and cannot be independently derived or verified by the end user.

313 European Commission (EC): Directive 98/79/EC of the Europen Parliament and of the Council of 27 October 1998 on in vitro diagnostic medical devices. Official Journal of the European Communities L 331/1 (1998) htrp://eur-lex,europa.eu/JOHtml.do?uri=OJ: 1;1998:391:SOM:EN:HTML [Accessed November 12, 2008]

114 UK Pharmacogenetics Study Group: Policy Isstes in Pharmacogenetics (2006) www.sussex.ac.uk/sociology/documents/ pgxpolicyissues 2006.pdf [Accessed November 12, 2008]

115 Hogarth S, Melzer D, Zimmern R: The regulation of commercial generic sesting services in the UK. A briefing for the Human Genetics Commission (2005) www.phpc.cum,ac.uk/epg/drc.pdf [Accessed November 12, 2008]

116 Secretary's Advisory Commirtee on Genetics, Heal rh, and Sociery (SACGHS): Coverage and Reimbursement of Genetic Tests and Services. US Department of Health and Human Services, USA (2006) www4.od,nih.gov/oba/sacghs/reports/cr report.pdf

[Accessed November 12, 2008]
117 Melzer D, Raven A, Detmer DE, Ling T, Zimmern RL: My Very Oum Medicine: What Mist I Know? Information Policy for Pharmacogentetics. Department of Public Health and Primary Care, University of Cambridge, UK (2003) www.phpc.cam.ac.uk/epg/Report.pdf [Accessed November 12, 2008]

118 Public Health Genomics European Nerwork Website. Online www.phgen.nrw.de/ [Accessed November 12, 2008]

119 Zimmern R, Burton H: Issues and Priorities of Public Health Genomics. Presentration at PHGEN, Bielefeld, 9 February 2006 (2006) www.phgen.nrw.de/typo3/fleadmin/ downloads/zimmern__burton_enterprise_ph-genomics.pdf [Accessed August 22, 2008]

120 European Commission. Recast of the Medical Devices Directives. Public Consultation hrtp://ec.europa,eu/enterprise/medica]_ devices/consult_recast_2008_en.hrm [Accessed November 5, 2008]

12] Maxwell A: Commission proposals threaten to "slow innovacion", says EDMA. Clinica (2008) www.clinica.co,uk/news2/sep_08/ commission_proposals_threaten_to_slow_ innoyation,_snys_edma [Accessed November 5, 2008]

122 Wright E, Roy F: Recasting the EU Medical Device Legislation. The Regulatory Affrirs Joumal Devices July/August 2008, 229-230 (2008) www.hhlaw.com/pressroom/newspubs/ pubderail.aspx?publication $=3817$ [Accessed November 12, 2008]

123 EuroGentest www.eurogentesc.org/unitg/ [Accessed November 12, 2008]

124 Bylander J: EU seeks input on device regulation revamp; industry says: 'too soon'. Medical Devices Today (2008) www.medicaldevicestoday.com/2008/07/ eu-seeks-inpur,heml [Accessed November 5, 2008]

125 EuroGentest: EuroGentest workshop on genetic testing and the in vitro diagnostic devices directive (2007) www.eurogentest.org/ documents2/1193125494407/Final_Report_ EuroGentest_IVDD_Workshop.pdf [Accessed August 22, 2008]

126 Secretary's Advisory Committee on Generics, Health, and Society (SACGHS): Realizing the Promise of Pharmacogenomics: Opportunities and Challenges, US Department of Health and Human Services (2008) www4.od, nih.gov/oba/sacghs/repores/ SACGHS_PGx_Report.pdf [Accessed November 12 2008]
127 European Commission (EC): Directive 2004/27/EC of the European Parliament and of the Council of 31 March 2004 amending Directive 2001/83/EC on the community code relaring to medicinal products for human use. Official Journal of the European Communities L 136-34-L 136/57 (2004) htep://eur-lex.europs.eu/JOHtml,do? uri=OJ: L:2004:136:SOM:EN:HTML

[Accessed November 12, 2008]

128 European Medicines Agency (EMEA): Guideline on Similar Biological Medicinal Products. CHMP/437/04 (2005) www.emea.europa.eu/pdfs/human/ biosimilar/043704en.pdf [Accessed November 12, 2008]

129 European Commission (EC): Directive 2003/63/EC of 25 June 2003 a mending Direcrive 2001/83/EC of the European Parliament and of the Council on the Community code relaring ro medicinal products for human use. Official Journal of the European Communities L 159-46-L 159/94 (2003)

htrp://eur-lex.europa.eu/JOHtml.do?uri=OJ: L:2003:159:SOM:EN:HTML

[Accessed November 12, 2008]

130 European Medicines Agency (EMEA): Guideline on Pharmacogenetics Briefing Meetings. EMEA/CHMP/ PGxWP/20227/2004 (2006) www.emen.europa.eu/pdfs/human/ pharmacogenerics/2022704en.pdf [Accessed November 12, 2008]

131 FDA and EMEA: Guiding principles Processing Joint FDA EMEA Voluntury Genomic Datn Submissions (VGDSs) within the framework of the Confidentiality Atrangement (2006) www.fda,gov/Cder/genomics/FDAEMEA,pdf [Accessed November 12, 2008]

132 European Commission; Proposal for a Council Regulation setsing up the Innovative Medicines Initiative Joint Undertaking (2007) www.madrimasd,org/proyectoseuropeos/ futuroPoliticalnv/docs/lMI_JTI_com2007.pdf [Accessed November 12, 2008)]

133 Innovative Medicines Injtiative. The Innovative Medicines Initiative (IMI) Research Agenda: Creating Biomedical Ro D Leadership for Europe to Benefit Patients and Society (2008) www.imi-europe.org/Lists/ IMIPublicarionDocumenrs/Strategic\%20 Research\%20Agenda\%20(Version\%202).pdf [Accessed December 12, 2008]

134 EuroGentest: Recommendarions for generic counselling related to genetic testing (2008) www.eurogentest,org/web/info/public/unit3/ final_recommendations_genetic_counselling. xheml

[Accessed November 12, 2008] 